Article

\title{
Supplier Selection Problems in Fashion Business Operations with Sustainability Considerations
}

\author{
Peng Jia ${ }^{1}$, Kannan Govindan ${ }^{2}$, Tsan-Ming Choi ${ }^{3, *}$ and Sivakumar Rajendran 4 \\ 1 Transportation Management College, Dalian Maritime University, 1 Linghai Road, \\ Dalian 116026, China; E-Mail: jiapeng@dlmu.edu.cn \\ 2 Department of Business and Economics, University of Southern Denmark, \\ Odense M DK-5230, Denmark; E-Mail: gov@sam.sdu.dk \\ 3 Institute of Textiles and Clothing, The Hong Kong Polytechnic University, \\ Hung Hom, Kowloon, Hong Kong, China \\ 4 Department of Mechanical Engineering, SSM Institute of Engineering and Technology, \\ Tamil Nadu 624002, India; E-Mail: hodautomobile@ssmiet.ac.in \\ * Author to whom correspondence should be addressed; E-Mail: jason.choi@polyu.edu.hk; \\ Tel.: +852-2766-6450.
}

Academic Editor: Marc A. Rosen

Received: 30 October 2014 / Accepted: 20 January 2015 / Published: 2 February 2015

\begin{abstract}
In recent years, sustainability has been a major focus of fashion business operations because fashion industry development causes harmful effects to the environment, both indirectly and directly. The sustainability of the fashion industry is generally based on several levels and this study focuses on investigating the optimal supplier selection problem for sustainable materials supply in fashion clothing production. Following the ground rule that sustainable development is based on the Triple Bottom Line (TBL), this paper has framed twelve criteria from the economic, environmental and social perspectives for evaluating suppliers. The well-established multi-criteria decision making tool Technique for Order of Preference by Similarity to Ideal Solution (TOPSIS) is employed for ranking potential suppliers among the pool of suppliers. Through a real case study, the proposed approach has been applied and some managerial implications are derived.
\end{abstract}

Keywords: sustainability; fashion industry; supplier selection; multi-criteria decision making; TOPSIS 


\section{Introduction}

The fashion industry, which includes textiles and apparel, is one of the most prominent industries in the world. It is also a big industry in developing countries, such as India. In fact, from the report of the India Brand Equity Foundation [1], the textile and clothing business sector in India currently contributes to $14 \%$ of industrial growth, and 35 million job opportunities. It occupies $17 \%$ of export earnings and has the potential to achieve a US\$80 billion global trade volume by 2020 . According to a report by the United Nation Environment Programme [2] and the European Commission [3], the textile and clothing industry is the world second biggest economic sector and it occupies $7 \%$ of the total world exports. Although the textile and fashion clothing sector has sustainable economic development, it is a threat to the environment and to social welfare owing to problems like pollution, wastes, human rights issues, etc. [4]. Therefore, achieving sustainability in textile and fashion business operations has to consider more than just economic development.

In fact, sustainable development can be defined in many different ways. For example, the World Commission on Environment and Development [5] defined sustainable development as the "development that meets the needs of the present without compromising the ability of future generations to meet their own needs". Moreover, sustainable development is balanced on three pillars, namely the social, the environmental and the economic aspects which are commonly known as the Triple Bottom Line (TBL) [6]. From the above definition and the TBL concept, the goal of sustainability in the textile and fashion clothing business operations may be interpreted as fulfilling the challenges in TBL, but the process of achieving the sustainability is not clear. Generally, the textile and fashion clothing business operation is based on its four levels of operations such as production of raw materials, production of fashion goods from raw materials, retail sales, and advertising and promotions; undoubtedly, these four levels are linked together. To achieve a complete sustainable development in textile and fashion clothing business operations, operations of all these four levels have to address the concerns in TBL.

In the literature, many former studies critically analyzed the textile and fashion industry impacts on social welfare and the environment [7]. To be specific, Diabat et al. [8] described that industries, especially in the textile sectors, are under pressure to implement sustainable practices in their operations to amend the environmental performances. They analyzed and revealed that adoption of safety standards, adoption of green practices, community economic welfare, health and safety issues, and employment stability are the five influential enablers to adopt sustainable supply chain management in Indian textile industries. Gardetti and Torres [9] mentioned that the cheap labor issue in textile and clothing industry relates to politics and the international trading agreements. In addition, they emphasized that abuses of working conditions, violation of human rights by low wages, and long working hours are typically seen in these industries. Baskaran et al. [10] examined the garment manufacturers and their suppliers (suppliers to manufacturers) in the Indian textile and clothing industry sector based on social and environmental criteria such as discrimination, abuse of human right, child labor, long working hours, unfair competition and pollution. Their study indicated that long working hours and child labor are serious issues on the suppliers' side and, pollution and unfair competition are the major concerns on the manufacturer side. Lo et al. [11] revealed that environmental management system is a significant liability for today's textile and fashion industries. 
They proved this by providing empirical evidence that the adaptation of an environmental management system has positive impacts on a firm's financial performance. Seuring and Goldbach [12] explained in their research that the textile and fashion supply chains are frequently blamable for environmental and social problems during the production process. Their case study report showed the ways to enhance the sustainability performance in textile and fashion supply chain during the production of environmentally competitive products at an admissible price. Blackburn [13] described that water, chemicals, asset stripping of non-renewable resources, waste, and transport are five main environmental issues that make the textile and clothing production operations unsustainable. Gardetti and Torres [9] found that the textile and fashion industry make a remarkable contribution to the economy but it hurts the environment and society from the perspective of sustainability. Aakko and Koskennurmi-Sivonen [4] indicated that until recent years sustainable development and fashion could not go hand-in-hand, but there are changes nowadays [14]. Choi [15] analytically examined the optimal apparel supplier selection problem in the presence of carbon footprint taxation scheme via a dynamic programming formulation. Most recently, Wang et al. [16] explored the role played by the government in affecting the fashion supply chain gaming structure with sustainability concerns.

Observe that fast fashion is an industrial trend and more and more fashion companies are faster now than before in terms of the shortened lead time of product offering. Interestingly, fast fashion relates highly to sustainability. In the literature, Fulton and Lee [17] emphasized that fashion industries and consumers are both influenced by "fast fashion". They argued that technological advances can enhance sustainability in the fashion industry. Turber and Altuntas [18] examined the current sustainability situation of fast fashion companies by examining their corporate reports. They found that fast fashion companies are now putting a lot of emphasis on supplier compliance with ethical codes of conduct and imposing tighter control and auditing to improve the overall supply chain sustainability performance. In addition, they revealed that fast fashion companies also set important sustainability criteria for their suppliers. Li et al. [19] investigated the impacts of corporate social responsibility on fast fashion companies and the respective supply chains. They determined seven attributes based on the sustainable development theory. They further proposed seven factors that are critically important for developing the sustainability governance framework. Based on a real case analysis, they discussed the application of their proposed governance mechanism in practice. Most recently, Shen [20] conducted a case study on H\&M to reveal insights on sustainability programs in fast fashion business operations. From the above studies, there is no doubt that fast fashion relates highly to sustainability and this fact affects the selection of suppliers in the industry. For more related studies on fast fashion, please refer to Choi [21]; for the importance of sustainability to fashion, since the area is huge, interested readers can refer to Choi and Cheng [22] for the latest development on the topic.

The sustainability in fashion clothing production operations, with the emphasis on supplier selection, is the focus of this study. To be specific, the first part of this study is devoted to the development of criteria framework for evaluating suppliers. This criteria framework consists of 12 criteria based on TBL aspects such as cost, quality, on-time delivery, and rejection rate (the economic aspect); toxic chemical usage control, water consumption control, energy usage control and pollution control (the environmental aspect); and, restriction on under age labor, restriction on long working hours, human rights, care and safe guard mechanism for workers (the social aspect). The second part of this study focuses on ranking the sustainable suppliers based on their performance on 
the criteria framework using the multi-criteria decision making (MCDM) methodology called Technique for Order of Preference by Similarity to Ideal Solution (TOPSIS). The proposed model for sustainable business operation in fashion clothing industry has been successfully applied in the real case company which is situated in India. Several managerial implications are discussed.

The rest of the paper is structured as follows: The solution methodology for sustainable supplier selection is introduced in Section 2. The proposed application in the case company is illustrated in Section 3. Section 4 presents the findings and Section 5 discusses the managerial implications, conclusion, and future research.

\section{Solution Methodology for Sustainable Supplier Selection}

In this study, the solution methodology includes the criteria framework development as the first phase and evaluation of criteria and selection of sustainable supplier based on their performance over the criteria as the second phase. The criteria framework development phase is explained in Section 3 along with the real case study. The criteria evaluation (using fuzzy sets and fuzzy numbers), and the selection of supplier (using TOPSIS) are introduced and explained as follows.

\subsection{Fuzzy Sets and Fuzzy Numbers}

Generally, human judgments on performance of any model may vary from individuals to individuals due to their naturally uncertain and "ambiguous" perceptions [23]. To help and overcome the vagueness in the judgments, Zadeh [24] pioneered and proposed the classical Fuzzy Set Theory (FST) and it provides the mathematical proficiency to resolve the uncertainties by setting reliable membership functions. Observe that Bellman and Zadeh [25] are the pioneers who applied FST in the decision making process and they are the first ones who introduced and proposed the fuzzy multi-criteria decision making methodology.

Triangular fuzzy numbers (TFN) approach is utilized in this paper for modeling the opinions of decision makers (DM) on criteria and alterative performances owing to its ease in terms of usage and calculations. These features are important to enhance the real world application of the proposed approach. A TFN can be defined as $(a, b, c)$ where $a \leq b \leq c$ and it can be represented in terms of the membership function as shown in Figure 1 using the following FST definition:

Let $X$ be the item in the universe and $x$ be the elements contained in it, then the fuzzy subset $A$ in $X$ is mentioned by membership function $f_{A}(x)$ which is dependent on each element $x$ in $A$ and a real number between 0 and 1 .

$$
f_{A}(x)= \begin{cases}\frac{x-a}{b-a} & x<a, x<c, a \leq x \leq b \\ \frac{c-x}{c-b} & b \leq x \leq c\end{cases}
$$




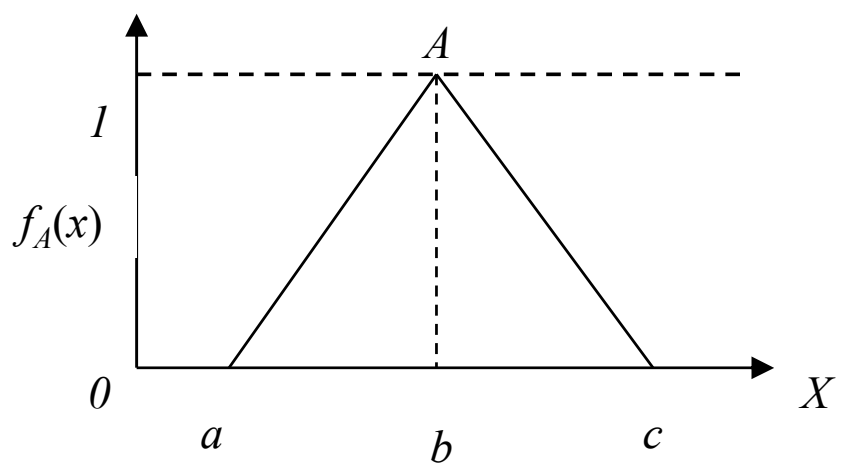

Figure 1. Membership function of triangular fuzzy number A.

Following the literature [24,26,27], some basic definitions of fuzzy concepts for the formal arithmetic operation of TFN in the proposed TOPSIS method are explained as follows.

The four basic arithmetic operations of two TFNs $\mathrm{A}-(\mathrm{a}, \mathrm{b}, \mathrm{c})$ and $\mathrm{B}-(\mathrm{a} 1, \mathrm{~b} 1, \mathrm{c} 1)$ are defined as,

$$
\begin{gathered}
\text { Addition operation: } \mathrm{A}(+) \mathrm{B}=(\mathrm{a}, \mathrm{b}, \mathrm{c})(+)(\mathrm{a} 1, \mathrm{~b} 1, \mathrm{c} 1)=(\mathrm{a}+\mathrm{a} 1, \mathrm{~b}+\mathrm{b} 1, \mathrm{c}+\mathrm{c} 1) \\
\text { Subtraction operation: } \mathrm{A}(-) \mathrm{B}=(\mathrm{a}, \mathrm{b}, \mathrm{c})(-)(\mathrm{a} 1, \mathrm{~b} 1, \mathrm{c} 1)=(\mathrm{a}-\mathrm{a} 1, \mathrm{~b}-\mathrm{b} 1, \mathrm{c}-\mathrm{c} 1) \\
\text { Multiplication operation: } \mathrm{kA}=(\mathrm{ka}, \mathrm{kb}, \mathrm{kc}) \\
\text { Inverse operation: }(\mathrm{A})^{-1}=\left(\frac{1}{c}, \frac{1}{b}, \frac{1}{a}\right)
\end{gathered}
$$

The distance between A and B can be found as follows,

$$
\mathrm{d}(\mathrm{A}, \mathrm{B})=\sqrt{\frac{1}{3}\left[(a-a 1)^{2}+(b-b 1)^{2}+(c-c 1)^{2}\right]}
$$

The aggregation of TFNs is represented as follows: Assume that the decision making team has $\mathrm{K}$ decision makers, and the perceptions of decision maker $S_{k}(k=1,2, \ldots, K)$ can be represented by the positive TFNs $R_{k}(k=1,2, \ldots, K)$, then the aggregated value of $R_{k}$ can be represented as:

$$
\mathrm{R}=(\mathrm{a}, \mathrm{b}, \mathrm{c}), \mathrm{k}=1,2, \ldots, \mathrm{K}
$$

where $\mathrm{a}=\min _{\mathrm{k}}\left\{\mathrm{a}_{\mathrm{k}}\right\}, \mathrm{b}=1 / \mathrm{k} \sum_{k=1}^{K} b_{k}$, and $\mathrm{c}=\max _{\mathrm{k}}\left\{\mathrm{c}_{\mathrm{k}}\right\}$.

\subsection{The TOPSIS Method}

TOPSIS is one of the most classic and important MCDM methodologies. It was proposed by Hwang and Yoon [28] with the concept of selecting alternatives by identifying the shortest distance from the positive ideal solution (PIS) and the farthest distance from negative ideal solution (NIS) [29]. TOPSIS is classified as a compromising method in MCDM with the notion that no ideal solution exists, and it permits decisive trade-offs and interaction among the multiple criteria. As a result, this argument implies that discrepancies in one criterion can be compensated or adjusted by some other criteria [30]. In fact, TOPSIS ranks the alternatives by calculating the closeness coefficient of each alternative obtained through PIS and NIS values. Observe that the TOPSIS and its related methods have been widely used in evaluating suppliers with green considerations in the literature (see, e.g., [31-37]).

To be specific, the TOPSIS method consists of the following critical steps [28,38-40]: 
Step 1: The aggregated TFN weight vector of each criterion calculated from individual decision makers' opinions (on intensity of importance) is given by

$$
\mathrm{W}=\left(\mathrm{w}_{1}, \mathrm{w}_{2}, \ldots, \mathrm{wj}_{\mathrm{j}}\right)
$$

where $\mathrm{j}=1,2,3, \ldots, \mathrm{n}$

Step 2: The normalized fuzzy decision matrix on alternative evaluation can be represented as: $\mathrm{N}=\left[\mathrm{n}_{\mathrm{ij}}\right] \mathrm{mxn}$.

where $\mathrm{B}$ and $\mathrm{C}$ are the sets of benefit and cost criteria in the criteria framework.

To avoid the complexity of mathematical operations in a decision process, the normalization process can be done as follows:

$$
n_{i j}=\left(\frac{a_{i j}}{c_{j}}, \frac{b_{i j}}{c_{j}}, \frac{c_{i j}}{c_{j}}\right), j \in B
$$

$c_{j}=\max _{i} c_{i j}, j \in B$

$$
n_{i j}=\left(\frac{a_{j}}{c_{i j}}, \frac{a_{j}}{b_{i j}}, \frac{a_{j}}{a_{i j}}\right), j \in C
$$

$\mathrm{a}_{\mathrm{j}}=\min _{\mathrm{i}} \mathrm{a}_{\mathrm{ij}}, \mathrm{j} \in \mathrm{C}$

Step 3: The weighted normalized decision matrix $\mathrm{p}_{\mathrm{ij}}$ can be calculated by multiplying the normalized decision matrix with the aggregated weight vector of criteria:

$$
P=\left[p_{i j}\right]_{m x n}, i=1,2, \ldots, m ; j=1,2, \ldots, n
$$

where $\mathrm{p}_{\mathrm{ij}}=\mathrm{n}_{\mathrm{ij}} \mathrm{w}_{\mathrm{j}}$

Step 4: The PIS $\left(\mathrm{S}^{+}\right)$and NIS $\left(\mathrm{S}^{-}\right)$, with respect to their definitions, can be calculated as follows:

$$
\begin{aligned}
& \mathrm{S}^{+}=\left(\mathrm{p}_{1}{ }^{+}, \mathrm{p}_{1}{ }^{+}, \ldots \mathrm{p}_{\mathrm{n}}{ }^{+}\right) \\
& \mathrm{S}^{-}=\left(\mathrm{p}_{1}{ }^{-}, \mathrm{p}_{1}{ }^{-}, \ldots \mathrm{p}_{\mathrm{n}}{ }^{-}\right)
\end{aligned}
$$

where $\mathrm{p}_{\mathrm{j}}^{+}=\max _{\mathrm{i}}\left[\mathrm{p}_{\mathrm{ij}}\right]$ and $\mathrm{p}_{\mathrm{j}}^{-}=\min _{\mathrm{i}}\left[\mathrm{p}_{\mathrm{ij}}\right], \mathrm{I}=1,2, \ldots, \mathrm{m} ; \mathrm{j}=1,2, \ldots, \mathrm{n}$

Step 5: The distance of each alternative from PIS and NIS can be determined easily by the following formulas:

$$
\begin{aligned}
& d_{i}^{+}=\sum_{j=1}^{n} d_{p}\left(p_{i j}, p_{j}^{+}\right), i=1,2, \ldots, m \\
& d_{i}^{-}=\sum_{j=1}^{n} d_{p}\left(p_{i j}, p_{j}^{-}\right), i=1,2, \ldots, m
\end{aligned}
$$

Step 6: The closeness coefficient $\left(\mathrm{CC}_{\mathrm{i}}\right)$ of each alternative can be estimated as follows:

$$
C C_{i}=\frac{d_{i}^{-}}{d_{i}^{-}+d_{i}^{+}}, i=1,2, \ldots, m
$$

Step 7: As the last step of the TOPSIS analysis, the ranking of alternatives is determined by comparing the closeness coefficient of each alternative, one by one, in a descending order. Alternative $\mathrm{Si}$ is closer to PIS and farther from NIS as $\mathrm{CC}_{\mathrm{i}}$ approaches to 1. 


\section{Application of the Proposed Model}

This section presents a real case for the application of the above proposed TOPSIS method for selecting the sustainable supplier based on TBL related criteria in the textile and clothing industry. The case study company is situated in India. The main function of this company is to design and fabricate fashion garments on a customized basis and export the products to countries worldwide. Though the case study company has had progressive growth in economic aspects, this study wants to explore further its performance including environmental and social aspects. Notice that the case company is sourcing materials for its fabrication process from various suppliers all over India. As an initial setup of the sustainable business operation in the case company, this study focuses on the selection of sustainable suppliers for the sourcing of sustainable materials for the fabrication process because sourcing is a core function of the case company. Hence, the objective of this study is to propose a TOPSIS model for sustainable supplier selection and evaluation. The proposed model consists of two phases: (i) The criteria framework development based on the economic, environmental and social aspects (i.e., the TBL); and (ii) the evaluation and selection scheme for sustainable supply based on the criteria with the proposed TOPSIS technique.

Observe that in the literature, studies which also employ TOPSIS for supplier evaluation with green considerations include [31-37]. This paper is similar to them in that TOPSIS is the major model for the analysis and the evaluation criteria relate to environmental sustainability. However, differently, the industry considered in this paper is the fashion industry whereas they consider other industries such as automobile, electronics, cement, etc. Furthermore, the criteria being evaluated are not the same, and the exact analytical model is also different. Last but not least, the model discussed in this paper is relatively easy to implement and can hence be conveniently applied in practice.

\subsection{Criteria Framework Development}

The first phase involves criteria framework development for sustainable supplier selection. An in-depth literature search on TBL related topics and extensive discussions with academic and industrial experts in the textile and fashion clothing field are utilized to develop the criteria framework in this paper. The preferred criteria in the framework are presented in Table 1. The developed criteria framework includes several criteria related to the economic, environmental and social sustainability. In the economic aspect, cost, quality, on-time delivery and control of rejection rate are selected as the criteria and they are also generally applied as the "traditional criteria" in the supplier selection process. The pre- and post-production processes of fibers and fabrics in textile operations have high impacts on the environment (such as toxic chemical usage, water usage, energy usage and pollution from hazardous materials) and hence they are considered as the environmental criteria in the criteria framework. Underage labor, long working hours, human rights issue, and safe guard mechanism are selected as the social criteria in the criteria framework development. Thus, in the criteria framework, $\mathrm{C} 1$ includes the cost-based criteria (i.e., the lowest value has the highest preference), and the other criteria are benefit-based criteria (i.e., the highest value the highest preference). 
Table 1. Criteria for evaluating and selecting sustainable suppliers [10,41].

\begin{tabular}{|c|c|c|}
\hline Criteria & Name & Definition \\
\hline $\mathrm{C} 1$ & Cost & Lowest product price without compromising the quality \\
\hline $\mathrm{C} 2$ & Quality & Ensure high quality control on the products \\
\hline $\mathrm{C} 3$ & On-time delivery & $\begin{array}{l}\text { Level of delivery on-time as per the } \\
\text { agreement with the customer }\end{array}$ \\
\hline $\mathrm{C} 4$ & Rejection rate control & Control on rejection rate of material \\
\hline $\mathrm{C} 5$ & Toxic chemical usage control & $\begin{array}{l}\text { Control or avoid the usage of toxic chemicals in } \\
\text { cultivation process and production process of textile. }\end{array}$ \\
\hline C6 & Water consumption control & Control the unwanted use of water in business operation. \\
\hline $\mathrm{C} 7$ & Energy usage control & $\begin{array}{l}\text { Control the unwanted use of energy } \\
\text { in business operation. }\end{array}$ \\
\hline $\mathrm{C} 8$ & Pollution control & $\begin{array}{l}\text { Control the improper waste disposal, } \\
\text { use of hazardous material in operation. }\end{array}$ \\
\hline C9 & Restriction on under age labor & Control the underage employment in business operation. \\
\hline $\mathrm{C} 10$ & $\begin{array}{l}\text { Restriction on } \\
\text { long working hours }\end{array}$ & $\begin{array}{l}\text { Control the forcing of workers to work more than } \\
\text { determined hours (apart from overtime) }\end{array}$ \\
\hline $\mathrm{C} 11$ & Human rights care & Basic facilities to labor, respect, etc. \\
\hline $\mathrm{C} 12$ & $\begin{array}{l}\text { Safe guard mechanism } \\
\text { for workers }\end{array}$ & Monitor the workers' health and safety \\
\hline
\end{tabular}

\subsection{Sustainable Supplier Selection Using TOPSIS}

In this proposed study, three possible "qualified" suppliers (S1, S2, S3) are thought to have the potential to support sustainable business operations and engaged for evaluation. The decision making team for evaluating the criteria's intensity of importance and supplier performance is composed of three experts from the material sourcing department (E1), the production department (E2) and the health and safety department (E3). The hierarchical structure of the decision model is presented in Figure 2. The questionnaire is prepared and distributed among the experts team for evaluation of criteria and suppliers. The expert members are asked to evaluate each criterion using the linguistic scale provided in the questionnaire to determine its intensity and evaluate the supplier's performance based on the selected criteria. A seven-point Likert scale is provided in the questionnaire to represent the experts perception. The linguistic scale for criteria evaluation and alternative evaluation is presented in Tables 2 and 3. The TOPSIS methodology is applied to solve the decision making problem. Tables 4 and 5 display the original assessment of the expert's opinions on criteria importance and suppliers performance. 


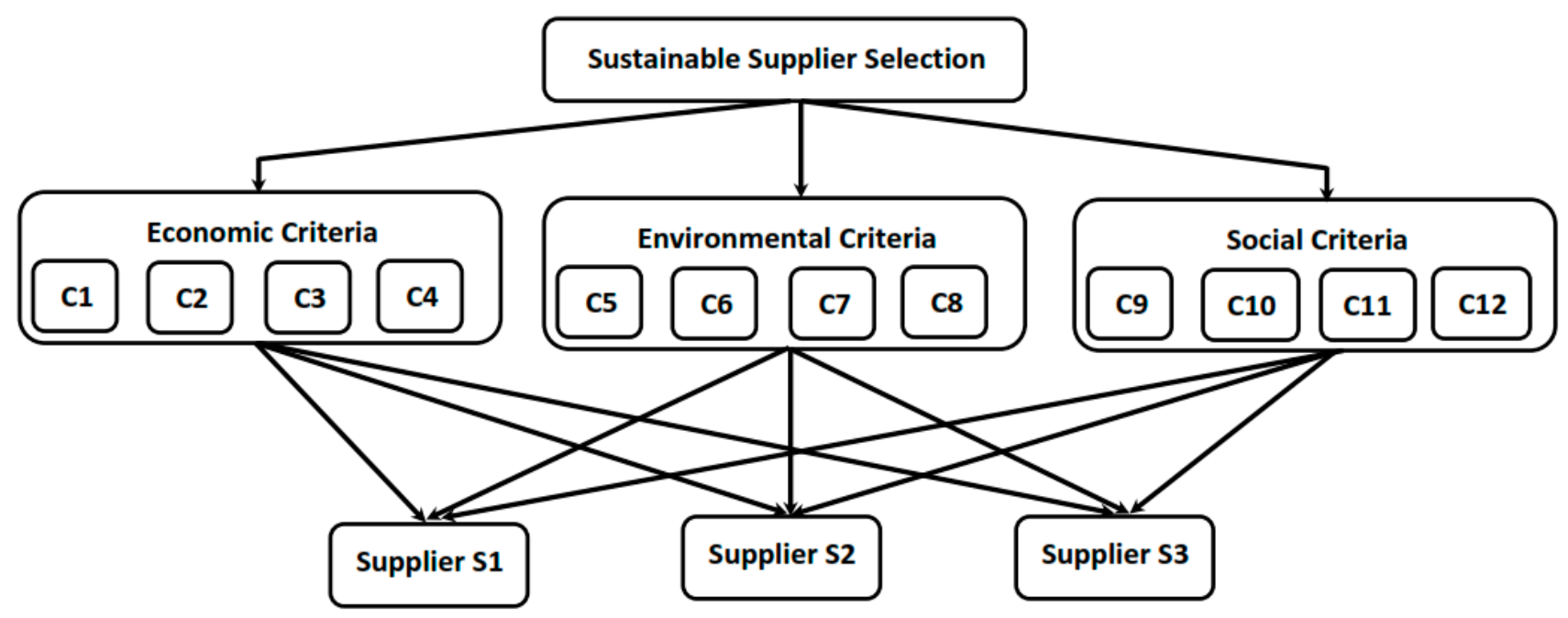

Figure 2. Hierarchical structure of sustainable supplier selection.

Table 2. Linguistic scale for rating the relative importance of criteria.

\begin{tabular}{cc}
\hline Linguistic Variable & Triangular Fuzzy Numbers \\
\hline Very low importance $(\mathrm{VL})$ & $(0,0,0.1)$ \\
Low importance $(\mathrm{L})$ & $(0,0.1,0.3)$ \\
Medium low importance $(\mathrm{ML})$ & $(0.1,0.3,0.5)$ \\
Medium importance $(\mathrm{M})$ & $(0.3,0.5,0.7)$ \\
Medium high importance $(\mathrm{MH})$ & $(0.5,0.7,0.9)$ \\
High importance $(\mathrm{H})$ & $(0.7,0.9,1)$ \\
Very high importance $(\mathrm{VH})$ & $(0.9,1,1)$ \\
\hline
\end{tabular}

Table 3. Linguistic scale for rating the performance of the suppliers.

\begin{tabular}{cc}
\hline Linguistic Variable & Triangular Fuzzy Numbers \\
\hline Very poor (VP) or very very low (VVL) & $(0,0,1)$ \\
Poor (P) or very low (VL) & $(0,1,3)$ \\
Medium poor (MP) or low (L) & $(1,3,5)$ \\
Medium (M) or average (AVG) & $(3,5,7)$ \\
Medium good (MG) or high (H) & $(5,7,9)$ \\
Good (G) or very high (VH) & $(7,9,10)$ \\
Very good (VG) or very very high (VVH) & $(9,10,10)$ \\
\hline
\end{tabular}


Table 4. Experts Assessment on importance of criteria and aggregated fuzzy weights of criteria.

\begin{tabular}{cccccccc}
\hline \multirow{2}{*}{ Criteria } & \multicolumn{3}{c}{$\begin{array}{c}\text { Linguistic Assessment of } \\
\text { Decision Makers }\end{array}$} & \multicolumn{3}{c}{ Fuzzy Criteria Weight } & \multirow{2}{*}{$\begin{array}{c}\text { Aggregated } \\
\text { Fuzzy Weight }\end{array}$} \\
\cline { 2 - 7 } & E1 & E2 & E3 & E1 & E2 & E3 & \\
\hline C1 & MH & H & MH & $(0.5,0.7,0.9)$ & $(0.7,0.9,1)$ & $(0.5,0.7,0.9)$ & $(0.5,0.77,1)$ \\
C2 & H & H & H & $(0.7,0.9,1)$ & $(0.7,0.9,1)$ & $(0.7,0.9,1)$ & $(0.7,0.90,1)$ \\
C3 & H & MH & MH & $(0.7,0.9,1)$ & $(0.5,0.7,0.9)$ & $(0.5,0.7,0.9)$ & $(0.5,0.77,1)$ \\
C4 & M & MH & M & $(0.3,0.5,0.7)$ & $(0.5,0.7,0.9)$ & $(0.3,0.5,0.7)$ & $(0.3,0.57,0.9)$ \\
C5 & H & MH & MH & $(0.7,0.9,1)$ & $(0.5,0.7,0.9)$ & $(0.5,0.7,0.9)$ & $(0.5,0.77,1)$ \\
C6 & MH & H & H & $(0.5,0.7,0.9)$ & $(0.7,0.9,1)$ & $(0.7,0.9,1)$ & $(0.5,0.83,1)$ \\
C7 & H & H & MH & $(0.7,0.9,1)$ & $(0.7,0.9,1)$ & $(0.5,0.7,0.9)$ & $(0.5,0.83,1)$ \\
C8 & H & MH & H & $(0.7,0.9,1)$ & $(0.5,0.7,0.9)$ & $(0.7,0.9,1)$ & $(0.5,0.83,1)$ \\
C9 & M & MH & M & $(0.3,0.5,0.7)$ & $(0.5,0.7,0.9)$ & $(0.3,0.5,0.7)$ & $(0.3,0.57,0.9)$ \\
C10 & M & ML & ML & $(0.3,0.5,0.7)$ & $(0.1,0.3,0.5)$ & $(0.1,0.3,0.5)$ & $(0.1,0.37,0.7)$ \\
C11 & H & M & MH & $(0.7,0.9,1)$ & $(0.3,0.5,0.7)$ & $(0.5,0.7,0.9)$ & $(0.3,0.70,1)$ \\
C12 & H & M & M & $(0.7,0.9,1)$ & $(0.3,0.5,0.7)$ & $(0.3,0.5,0.7)$ & $(0.3,0.63,1)$ \\
\hline
\end{tabular}

Table 5. Experts Assessment on performance of suppliers and aggregated fuzzy weights.

\begin{tabular}{|c|c|c|c|c|c|c|c|c|c|c|c|c|}
\hline \multirow{2}{*}{ Criteria } & \multicolumn{4}{|c|}{ Supplier S1 } & \multicolumn{4}{|c|}{ Supplier S2 } & \multicolumn{4}{|c|}{ Supplier S3 } \\
\hline & E1 & E2 & E3 & Aggregate & E1 & E2 & E3 & Aggregate & E1 & E2 & E3 & Aggregate \\
\hline $\mathrm{C} 1$ & $\mathrm{H}$ & $\mathrm{VH}$ & $\mathrm{VH}$ & $(5,8.33,10)$ & AVG & $\mathrm{H}$ & $\mathrm{H}$ & $(3,6.33,9)$ & AVG & AVG & $\mathrm{H}$ & $(3,5.67,9)$ \\
\hline $\mathrm{C} 2$ & $\mathrm{VH}$ & G & VH & $(7,9.00,10)$ & MG & MG & G & $(5,7.67,10)$ & M & M & G & $(3,6.33,10)$ \\
\hline $\mathrm{C} 3$ & G & $\mathrm{H}$ & $\mathrm{H}$ & $(5,7.67,10)$ & MG & VH & G & $(5,8.33,10)$ & $\mathrm{M}$ & $\mathrm{H}$ & G & $(3,7.00,10)$ \\
\hline $\mathrm{C} 4$ & $\mathrm{~L}$ & $\mathrm{~L}$ & $\mathrm{AVG}$ & $(1,3.67,7)$ & VL & $\mathrm{VL}$ & $\mathrm{AVG}$ & $(0,2.33,7)$ & $\mathrm{L}$ & AVG & $\mathrm{H}$ & $(1,5.00,9)$ \\
\hline $\mathrm{C} 5$ & G & MG & $\mathrm{VH}$ & $(5,8.33,10)$ & $\mathrm{M}$ & MG & MP & $(1,5.00,9)$ & $\mathrm{P}$ & $\mathrm{L}$ & AVG & $(0,3.00,7)$ \\
\hline $\mathrm{C} 6$ & MG & $\mathrm{H}$ & AVG & $(3,6.33,9)$ & MP & $\mathrm{L}$ & M & $(1,3.67,7)$ & MP & MP & $\mathrm{L}$ & $(1,3.00,5)$ \\
\hline $\mathrm{C} 7$ & M & MP & AVG & $(1,4.33,7)$ & MG & $\mathrm{H}$ & AVG & $(3,6.33,9)$ & $\mathrm{M}$ & $\mathrm{L}$ & AVG & $(1,4.33,7)$ \\
\hline $\mathrm{C} 8$ & MG & G & $\mathrm{H}$ & $(5,7.67,10)$ & MP & AVG & $\mathrm{VL}$ & $(0,3.00,7)$ & M & AVG & M & $(3,5.00,7)$ \\
\hline C9 & G & VH & $\mathrm{H}$ & $(5,8.33,10)$ & M & M & $\mathrm{H}$ & $(3,5.67,9)$ & $\mathrm{H}$ & VH & AVG & $(3,7.00,10)$ \\
\hline $\mathrm{C} 10$ & M & MP & $\mathrm{L}$ & $(1,3.67,7)$ & MP & $\mathrm{L}$ & AVG & $(1,3.67,7)$ & AVG & AVG & $\mathrm{H}$ & $(3,5.67,9)$ \\
\hline $\mathrm{C} 11$ & $\mathrm{H}$ & G & G & $(5,8.33,10)$ & MG & $\mathrm{H}$ & VH & $(5,7.67,10)$ & $\mathrm{G}$ & $\mathrm{G}$ & MG & $(5,8.33,10)$ \\
\hline $\mathrm{C} 12$ & G & G & $\mathrm{M}$ & $(3,7.67,10)$ & $\mathrm{H}$ & VH & $\mathrm{H}$ & $(5,7.67,10)$ & G & $\mathrm{H}$ & MG & $(5,7.67,10)$ \\
\hline
\end{tabular}




\subsection{Sensitivity Analysis}

Sensitivity analysis is used to understand how the variation of inputs may influence the output of the analytical model. Generally, the sensitivity analysis is applied by slightly varying the weights of the input and noting the effects of output in the decision model. In this study, sensitivity analysis has been conducted through 24 experiments by varying the criteria weights in the proposed model and observing the ranking of the potential suppliers.

\section{Results and Findings}

From the technical analysis conducted in Section 3, the following research results and findings are obtained. First, upon the application of the proposed methodology, the results from each step as described in the earlier solution methodology section are tabulated in Tables 6-8. To be specific, the normalized and weighted decision matrix, the distance of each supplier from PIS and NIS with respect to each criterion and the closeness coefficient of each supplier are shown respectively in the tables. Note that the final result of the application of TOPSIS methodology is summarized in Table 8. The ranking of suppliers is sorted in a descending order based on the closeness coefficient value, and the final ranking of suppliers is: $\mathrm{S} 1>\mathrm{S} 2>\mathrm{S} 3$.

Second, in the sensitivity analysis, Table 9 summarizes the experimental weights of criteria and the numerical solutions. Figure 3 further presents the graphical view of the results. the computational results show that the ranking order $\mathrm{S} 1>\mathrm{S} 2>\mathrm{S} 3$ has not been changed in 15 experiments, and in 9 experiments it has been changed to $\mathrm{S} 1>\mathrm{S} 3>\mathrm{S} 2$. The analysis hence proves that the decision making process is rather insensitive to changes in the criteria weights and supplier S3 is always ranked first in all experiments.

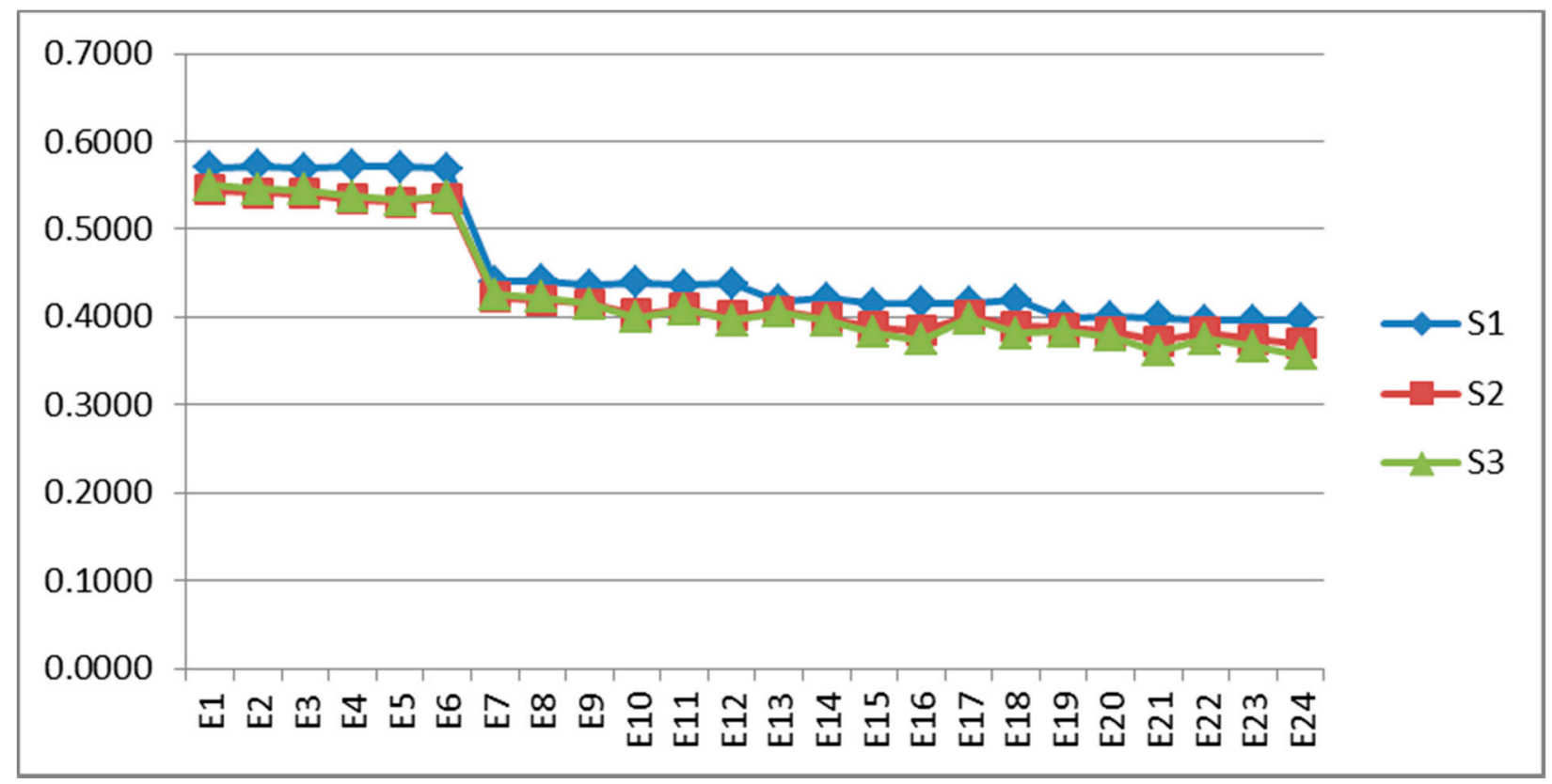

Figure 3. Results of sensitivity analysis. 
Table 6. Normalized and weighed fuzzy decision matrix.

\begin{tabular}{|c|c|c|c|c|c|c|}
\hline \multirow[t]{2}{*}{ Criteria } & \multicolumn{3}{|c|}{ Normalized Fuzzy-Decision Matrix } & \multicolumn{3}{|c|}{ Weighted Normalized Fuzzy Decision Matrix } \\
\hline & S1 & $\mathbf{S 2}$ & S3 & S1 & $\mathbf{S 2}$ & $\mathbf{S 3}$ \\
\hline $\mathrm{C} 1$ & $(0.30,0.36,0.60)$ & $(0.33,0.47,1.00)$ & $(0.33,0.53,1.00)$ & $(0.15,0.28,0.60)$ & $(0.17,0.36,1.00)$ & $(0.17,0.41,1.00)$ \\
\hline $\mathrm{C} 2$ & $(0.70,0.90,1.00)$ & $(0.50,0.77,1.00)$ & $(0.30,0.63,1.00)$ & $(0.49,0.81,1.00)$ & $(0.35,0.69,1.00)$ & $(0.21,0.57,1.00)$ \\
\hline $\mathrm{C} 3$ & $(0.50,0.77,1.00)$ & $(0.50,0.83,1.00)$ & $(0.30,0.70,1.00)$ & $(0.25,0.59,1.00)$ & $(0.25,0.64,1.00)$ & $(0.15,0.54,1.00)$ \\
\hline $\mathrm{C} 4$ & $(0.10,0.37,0.70)$ & $(0.00,0.23,0.70)$ & $(0.10,0.50,0.90)$ & $(0.03,0.21,0.63)$ & $(0.00,0.13,0.63)$ & $(0.03,0.29,0.81)$ \\
\hline $\mathrm{C} 5$ & $(0.50,0.83,1.00)$ & $(0.10,0.50,0.90)$ & $(0.00,0.30,0.70)$ & $(0.25,0.64,1.00)$ & $(0.05,0.39,0.90)$ & $(0.00,0.23,0.70)$ \\
\hline C6 & $(0.30,0.63,0.90)$ & $(0.10,0.37,0.70)$ & $(0.10,0.30,0.50)$ & $(0.15,0.53,0.90)$ & $(0.05,0.30,0.70)$ & $(0.05,0.25,0.50)$ \\
\hline $\mathrm{C} 7$ & $(0.10,0.43,0.70)$ & $(0.30,0.63,0.90)$ & $(0.10,0.43,0.70)$ & $(0.05,0.36,0.70)$ & $(0.15,0.53,0.90)$ & $(0.05,0.36,0.70)$ \\
\hline $\mathrm{C} 8$ & $(0.50,0.77,1.00)$ & $(0.00,0.30,0.70)$ & $(0.30,0.50,0.70)$ & $(0.25,0.64,1.00)$ & $(0.00,0.25,0.70)$ & $(0.15,0.42,0.70)$ \\
\hline C9 & $(0.50,0.83,1.00)$ & $(0.30,0.57,0.90)$ & $(0.30,0.70,1.00)$ & $(0.15,0.47,0.90)$ & $(0.09,0.32,0.81)$ & $(0.09,0.40,0.90)$ \\
\hline $\mathrm{C} 10$ & $(0.10,0.37,0.70)$ & $(0.10,0.37,0.70)$ & $(0.30,0.57,0.90)$ & $(0.01,0.14,0.49)$ & $(0.01,0.14,0.49)$ & $(0.03,0.21,0.63)$ \\
\hline $\mathrm{C} 11$ & $(0.50,0.83,1.00)$ & $(0.50,0.77,1.00)$ & $(0.50,0.83,1.00)$ & $(0.15,0.58,1.00)$ & $(0.15,0.54,1.00)$ & $(0.15,0.58,1.00)$ \\
\hline $\mathrm{C} 12$ & $(0.30,0.77,1.00)$ & $(0.50,0.77,1.00)$ & $(0.50,0.77,1.00)$ & $(0.09,0.48,1.00)$ & $(0.15,0.48,1.00)$ & $(0.15,0.48,1.00)$ \\
\hline
\end{tabular}

Table 7. Distance between suppliers and $\mathrm{S}^{+}, \mathrm{S}^{-}$with respect to each criterion.

\begin{tabular}{ccccccccccccc}
\hline & $\mathbf{C 1}$ & $\mathbf{C 2}$ & $\mathbf{C 3}$ & $\mathbf{C 4}$ & $\mathbf{C 5}$ & $\mathbf{C 6}$ & $\mathbf{C 7}$ & $\mathbf{C 8}$ & $\mathbf{C 9}$ & $\mathbf{C 1 0}$ & $\mathbf{C 1 1}$ & $\mathbf{C 1 2}$ \\
\hline $\mathrm{d}\left(\mathrm{S} 1, \mathrm{~S}^{+}\right)$ & 0.68 & 0.31 & 0.49 & 0.75 & 0.48 & 0.57 & 0.68 & 0.48 & 0.58 & 0.81 & 0.55 & 0.60 \\
$\mathrm{~d}\left(\mathrm{~S} 2, \mathrm{~S}^{+}\right)$ & 0.60 & 0.42 & 0.48 & 0.79 & 0.66 & 0.70 & 0.57 & 0.74 & 0.66 & 0.81 & 0.56 & 0.57 \\
$\mathrm{~d}\left(\mathrm{~S} 3, \mathrm{~S}^{+}\right)$ & 0.59 & 0.52 & 0.56 & 0.70 & 0.75 & 0.76 & 0.68 & 0.62 & 0.63 & 0.75 & 0.55 & 0.57 \\
\hline & $\mathbf{C 1}$ & $\mathbf{C 2}$ & $\mathbf{C 3}$ & $\mathbf{C 4}$ & $\mathbf{C 5}$ & $\mathbf{C 6}$ & $\mathbf{C 7}$ & $\mathbf{C 8}$ & $\mathbf{C 9}$ & $\mathbf{C 1 0}$ & $\mathbf{C 1 1}$ & $\mathbf{C 1 2}$ \\
\hline $\mathrm{d}\left(\mathrm{S} 1, \mathrm{~S}^{-}\right)$ & 0.27 & 0.65 & 0.56 & 0.29 & 0.57 & 0.48 & 0.34 & 0.57 & 0.47 & 0.21 & 0.55 & 0.53 \\
$\mathrm{~d}\left(\mathrm{~S} 2, \mathrm{~S}^{-}\right)$ & 0.51 & 0.59 & 0.57 & 0.29 & 0.46 & 0.33 & 0.48 & 0.33 & 0.40 & 0.21 & 0.54 & 0.53 \\
$\mathrm{~d}\left(\mathrm{~S} 3, \mathrm{~S}^{-}\right)$ & 0.51 & 0.55 & 0.54 & 0.40 & 0.33 & 0.22 & 0.34 & 0.35 & 0.46 & 0.29 & 0.55 & 0.53 \\
\hline
\end{tabular}


Table 8. Calculation of $\mathrm{d}^{+}, \mathrm{d}^{-}$and $\mathrm{CC}_{\mathrm{i}}$.

\begin{tabular}{ccccc}
\hline Supplier & $\mathbf{d}^{+}$ & $\mathbf{d}^{-}$ & $\mathbf{C C}_{\mathbf{i}}$ & Rank \\
\hline S1 & 7.00 & 5.50 & 0.4398 & 1 \\
S2 & 7.57 & 5.24 & 0.4093 & 2 \\
S3 & 7.69 & 5.07 & 0.3972 & 3 \\
\hline
\end{tabular}

Table 9. Numerical results of sensitivity analysis.

\begin{tabular}{|c|c|c|c|c|c|c|c|c|}
\hline \multirow{2}{*}{$\begin{array}{c}\text { Experiment } \\
\text { No. }\end{array}$} & \multicolumn{4}{|c|}{ Definition } & \multirow{2}{*}{ S1 } & \multirow{2}{*}{ S2 } & \multirow{2}{*}{ S3 } & \multirow{2}{*}{ Ranking } \\
\hline & $\mathrm{C} 1, \mathrm{C} 2, \mathrm{C} 3=$ & $\mathrm{C} 4, \mathrm{C} 5, \mathrm{C} 6=$ & $\mathrm{C} 7, \mathrm{C} 8, \mathrm{C} 9=$ & $\mathrm{C} 10, \mathrm{C} 11, \mathrm{C12}=$ & & & & \\
\hline E1 & $(0.1,0.37,0.7)$ & $(0.3,0.63,1)$ & $(0.5,0.83,1)$ & $(0.7,0.9,1)$ & 0.5705 & 0.5443 & 0.5496 & $\mathrm{~S} 1>\mathrm{S} 3>\mathrm{S} 2$ \\
\hline E2 & $(0.1,0.37,0.7)$ & $(0.3,0.63,1)$ & $(0.7,0.9,1)$ & $(0.5,0.83,1)$ & 0.5718 & 0.5416 & 0.5462 & $\mathrm{~S} 1>\mathrm{S} 3>\mathrm{S} 2$ \\
\hline E3 & $(0.1,0.37,0.7)$ & $(0.5,0.83,1)$ & $(0.3,0.63,1)$ & $(0.7,0.9,1)$ & 0.5690 & 0.5405 & 0.5446 & $\mathrm{~S} 1>\mathrm{S} 3>\mathrm{S} 2$ \\
\hline E4 & $(0.1,0.37,0.7)$ & $(0.5,0.83,1)$ & $(0.7,0.9,1)$ & $(0.3,0.63,1)$ & 0.5719 & 0.5343 & 0.5370 & $\mathrm{~S} 1>\mathrm{S} 3>\mathrm{S} 2$ \\
\hline E5 & $(0.1,0.37,0.7)$ & $(0.7,0.9,1)$ & $(0.3,0.63,1)$ & $(0.5,0.83,1)$ & 0.5708 & 0.5313 & 0.5334 & $\mathrm{~S} 1>\mathrm{S} 3>\mathrm{S} 2$ \\
\hline E6 & $(0.1,0.37,0.7)$ & $(0.7,0.9,1)$ & $(0.5,0.83,1)$ & $(0.3,0.63,1)$ & 0.5692 & 0.5348 & 0.5376 & $\mathrm{~S} 1>\mathrm{S} 3>\mathrm{S} 2$ \\
\hline E7 & $(0.3,0.63,1)$ & $(0.1,0.37,0.7)$ & $(0.5,0.83,1)$ & $(0.7,0.9,1)$ & 0.4402 & 0.4227 & 0.4259 & $\mathrm{~S} 1>\mathrm{S} 3>\mathrm{S} 2$ \\
\hline E8 & $(0.3,0.63,1)$ & $(0.1,0.37,0.7)$ & $(0.7,0.9,1)$ & $(0.5,0.83,1)$ & 0.4414 & 0.4197 & 0.4222 & $\mathrm{~S} 1>\mathrm{S} 3>\mathrm{S} 2$ \\
\hline E9 & $(0.3,0.63,1)$ & $(0.5,0.83,1)$ & $(0.1,0.37,0.7)$ & $(0.7,0.9,1)$ & 0.4360 & 0.4148 & 0.4153 & $\mathrm{~S} 1>\mathrm{S} 3>\mathrm{S} 2$ \\
\hline E10 & $(0.3,0.63,1)$ & $(0.5,0.83,1)$ & $(0.7,0.9,1)$ & $(0.1,0.37,0.7)$ & 0.4397 & 0.4033 & 0.3989 & $\mathrm{~S} 1>\mathrm{S} 2>\mathrm{S} 3$ \\
\hline E11 & $(0.3,0.63,1)$ & $(0.7,0.9,1)$ & $(0.1,0.37,0.7)$ & $(0.5,0.83,1)$ & 0.4359 & 0.4096 & 0.4087 & $\mathrm{~S} 1>\mathrm{S} 2>\mathrm{S} 3$ \\
\hline E12 & $(0.3,0.63,1)$ & $(0.7,0.9,1)$ & $(0.5,0.83,1)$ & $(0.1,0.37,0.7)$ & 0.4383 & 0.4011 & 0.3961 & $\mathrm{~S} 1>\mathrm{S} 2>\mathrm{S} 3$ \\
\hline E13 & $(0.5,0.83,1)$ & $(0.1,0.37,0.7)$ & $(0.3,0.63,1)$ & $(0.7,0.9,1)$ & 0.4184 & 0.4062 & 0.4054 & $\mathrm{~S} 1>\mathrm{S} 2>\mathrm{S} 3$ \\
\hline E14 & $(0.5,0.83,1)$ & $(0.1,0.37,0.7)$ & $(0.7,0.9,1)$ & $(0.3,0.63,1)$ & 0.4210 & 0.3992 & 0.3966 & $\mathrm{~S} 1>\mathrm{S} 2>\mathrm{S} 3$ \\
\hline E15 & $(0.5,0.83,1)$ & $(0.5,0.83,1)$ & $(0.1,0.37,0.7)$ & $(0.7,0.9,1)$ & 0.4152 & 0.3889 & 0.3828 & $\mathrm{~S} 1>\mathrm{S} 2>\mathrm{S} 3$ \\
\hline E16 & $(0.5,0.83,1)$ & $(0.5,0.83,1)$ & $(0.7,0.9,1)$ & $(0.1,0.37,0.7)$ & 0.4163 & 0.3840 & 0.3743 & $\mathrm{~S} 1>\mathrm{S} 2>\mathrm{S} 3$ \\
\hline E17 & $(0.5,0.83,1)$ & $(0.7,0.9,1)$ & $(0.1,0.37,0.7)$ & $(0.3,0.63,1)$ & 0.4160 & 0.4014 & 0.3985 & $\mathrm{~S} 1>\mathrm{S} 2>\mathrm{S} 3$ \\
\hline E18 & $(0.5,0.83,1)$ & $(0.7,0.9,1)$ & $(0.3,0.63,1)$ & $(0.1,0.37,0.7)$ & 0.4197 & 0.3896 & 0.3813 & $\mathrm{~S} 1>\mathrm{S} 2>\mathrm{S} 3$ \\
\hline E19 & $(0.7,0.9,1)$ & $(0.1,0.37,0.7)$ & $(0.3,0.63,1)$ & $(0.5,0.83,1)$ & 0.3990 & 0.3873 & 0.3830 & $\mathrm{~S} 1>\mathrm{S} 2>\mathrm{S} 3$ \\
\hline E20 & $(0.7,0.9,1)$ & $(0.1,0.37,0.7)$ & $(0.5,0.83,1)$ & $(0.3,0.63,1)$ & 0.4003 & 0.3834 & 0.3778 & $\mathrm{~S} 1>\mathrm{S} 2>\mathrm{S} 3$ \\
\hline E21 & $(0.7,0.9,1)$ & $(0.3,0.63,1)$ & $(0.1,0.37,0.7)$ & $(0.5,0.83,1)$ & 0.3989 & 0.3732 & 0.3610 & $\mathrm{~S} 1>\mathrm{S} 2>\mathrm{S} 3$ \\
\hline E22 & $(0.7,0.9,1)$ & $(0.3,0.63,1)$ & $(0.5,0.83,1)$ & $(0.1,0.37,0.7)$ & 0.3965 & 0.3822 & 0.3755 & $\mathrm{~S} 1>\mathrm{S} 2>\mathrm{S} 3$ \\
\hline E23 & $(0.7,0.9,1)$ & $(0.5,0.83,1)$ & $(0.1,0.37,0.7)$ & $(0.3,0.63,1)$ & 0.3958 & 0.3751 & 0.3662 & $\mathrm{~S} 1>\mathrm{S} 2>\mathrm{S} 3$ \\
\hline E24 & $(0.7,0.9,1)$ & $(0.5,0.83,1)$ & $(0.3,0.63,1)$ & $(0.1,0.37,0.7)$ & 0.3969 & 0.3699 & 0.3569 & $\mathrm{~S} 1>\mathrm{S} 2>\mathrm{S} 3$ \\
\hline
\end{tabular}

\section{Managerial Implications, Conclusions, and Future Research}

Sustainable development is crucial in the modern business world. In this study, the optimal supplier selection problem in the textile and fashion clothing industry with sustainability considerations has been examined. To be specific, this paper has proposed the fuzzy MCDM problem for finding the optimal supplier with the consideration of the economic, environmental, and social sustainability. The formal analytical model has been proposed and the analysis has been conducted with a real case study in Sections 2 and 3. As the concluding remarks, some major managerial implications are highlighted in the following:

(1). To formulate the sustainable supplier selection problem, managers in the textile and fashion industry can develop the criteria framework by making reference to the literature and the 
industrial practices as what we proposed in this paper. For example, following our approach, twelve criteria have been framed and their importance has been evaluated by a decision making team comprised of three experts from the case study company. In modeling, this study has applied the commonly used triangular fuzzy linguistic scale to quantify the expert's opinion on criteria evaluation and supplier performance over the criteria. The well-established TOPSIS methodology has been used to analyze the supplier performance on each criterion based on the compromising concept of the TOPSIS methodology. The best sustainable supplier is selected based on the highest closeness coefficient value. This approach is applicable, easily customizable, and implementable in practice.

(2). From the sensitivity analysis, the proposed model in this paper is found to be stable and the optimal recommendation (i.e., supplier S1) is not affected by changes of the input weights. This shows the strength of the proposed model in finding the optimal solution.

(3). With the criteria being defined, the upstream suppliers and the manufacturer can enhance their own level of sustainability by working diligently on the areas highlighted by the important criteria. By forming a strategic partnership, they can potentially improve the sustainability of their business operations significantly.

(4). Note that the criteria framework developed in this study can be applied for other functions in business operations of the case company. Moreover, managers of related industries can also apply the proposed model to evaluate their suppliers with the sustainability considerations.

For further studies, since this study only focuses on sustainability in the material sourcing function of the company, other functions could also be studied in the future. In other words, an important future research area is to enlarge the scope of this paper by considering the industry in a wider sense [42]. Moreover, owing to resource limitations, only a limited number of factors and a limited number of respondents are utilized in the current model development and analysis, more factors could be incorporated into the extend model in future research using different MCDM tools. For example, one could consider sustainability as the ultimate outcome of supply chain dynamics, and hence the respective factors can be considered [43-50].

\section{Acknowledgments}

The authors are very grateful for the kind comments raised by the Assistant Editor Jie Gu, and the anonymous reviewers which led to important improvement of this paper. Peng Jia's research is supported by National Natural Science Foundation of China (Grant No. 71303026), the Scientific Research Foundation for the Returned Overseas Chinese Scholars, State Education Ministry (46th, [2013]693). Kannan Govindan's research is partially supported by a grant from Forsknings-og Innovationsstyrelsen for project 12-132697. Tsan Ming Choi's research is partially supported by the research grant numbered "PolyU 155013/14B".

\section{Author Contributions}

All authors have good contributions to the development of this paper. In particular, Peng Jia contributed in the writing part. Kannan Govindan contributed in the theoretical development and the 
writing part. Sivakumar Rajendran contributed in the writing and case study part of the paper. Tsan-Ming Choi contributed to refining and strengthening the paper's expositions and managerial implications. He also helped with the paper's revisions.

\section{Conflicts of Interest}

The authors declare no conflict of interest.

\section{References}

1. India Brand Equity Foundation (IBEF). Textile Industry in India. Available online: http://www. ibef.org/pages/36301 (accessed on 9 October 2014).

2. United Nations Environment Programme (UNEP). TEXTILES-Fashion that doesn't cost the Earth. Available online: http:/www.unep.fr/shared/Publications/other/WEBx0008xPA/ textiles.pdf (accessed on 9 October 2014).

3. European Commission (EC). Sustainability of textiles. Issue paper, 2013. Available online: http://www.ec.europa.eu/environment/industry/retail/pdf/issue_paper_textiles.pdf (accessed on 9 October 2014).

4. Aakko, M.; Koskennurmi-Sivonen, R. Designing sustainable fashion: Possibilities and challenges. Res. J. Text. Appar. 2013, 17, 13-22.

5. World Commission on Environment and Development (WCED). Our Common Future; Oxford University Press: Oxford, UK, 1987; Volume 383.

6. Elkington, J. Cannibals with Forks: The Triple Bottom Line of 21st Century; Capstone Publishing: Oxford, UK, 1997.

7. Choi, T.M.; Chiu, C.H.; Govindan, K.; Yue, X. Sustainable fashion supply chain management: The European scenario. Eur. Manag. J. 2014, 32, 821-822.

8. Diabat, A.; Kannan, D.; Mathiyazhagan, K. Analysis of enablers for implementation of sustainable supply chain management-A textile case. J. Clean. Prod. 2014, 83, 391-403.

9. Gardetti, M.Á.; Torres, A.L. Sustainability in Fashion and Textiles; Greenleaf Publishing: Sheffield, UK, 2013.

10. Baskaran, V.; Nachiappan, S.; Rahman, S. Indian textile suppliers' sustainability evaluation using the grey approach. Int. J. Prod. Econ. 2012, 135, 647-658.

11. Lo, C.K.; Yeung, A.C.; Cheng, T.C.E. The impact of environmental management systems on financial performance in fashion and textiles industries. Int. J. Prod. Econ. 2012, 135, 561-567.

12. Seuring, S.; Goldbach, M. Managing sustainability performance in the textile chain. Manag. Bus. Case Sustain. Integr. Soc. Environ. Econ. Perform. 2006, 13, 465-477.

13. Blackburn, R.S. Sustainable Textiles: Life Cycle and Environmental Impact; Woodhead Publishing Limited: Cambridge, UK, 2009.

14. Clark, H. Slow + fashion-An oxymoron-Or a promise for the future? Fash. Theory J. Dress Body Cult. 2008, 12, 427-446.

15. Choi, T.M. Optimal apparel supplier selection with forecast updates under carbon emission taxation scheme. Comput. Oper. Res. 2013, 40, 2646-2655. 
16. Wang, K.; Zhao, Y.; Cheng, Y.; Choi, T.M. Cooperation or competition? Channel choice for a remanufacturing fashion supply chain with government subsidy. Sustainability 2014, 6, 7292-7310.

17. Fulton, K.B.; Lee, S.E. An overview of sustainability in the fashion industry. Int. J. Environ. Cult. Econ. Soc. Sustain. 2010, 6, 1-14.

18. Turber, D.; Altuntas, C. Sustainable supply chain management in the fast fashion industry: An analysis of corporate reports. Eur. Manag. J. 2014, 32, 837-849.

19. Li, Y.; Zhao, X.; Shi, D.; Li, X. Governance of sustainable supply chains in the fast fashion industry. Eur. Manag. J. 2014, 32, 823-836.

20. Shen, B. Sustainable fashion supply chain: Lessons from H\&M. Sustainability 2014, 6, 6236-6249.

21. Choi, T.M. Fast Fashion Systems: Theories and Applications; CRC Press: London, UK, 2014.

22. Choi, T.M.; Cheng, T.C.E. Sustainable Fashion Supply Chain Management; Springer: New York, NY, USA, 2015.

23. Saremi, M.; Mousavi, S.F.; Sanayei, A. TQM consultant selection in SMEs with TOPSIS under fuzzy environment. Expert Syst. Appl. 2009, 36, 2742-2749.

24. Zadeh, L.A. Fuzzy Sets. Inf. Control. 1965, 8, 338-353.

25. Bellman, R.E.; Zadeh, L.A. Decision-making in a fuzzy environment. Manag. Sci. 1970, 17, 141-164.

26. Zadeh, L.A. A fuzzy algorithmic approach to the definition of complex or imprecise concepts. Int. J. Man Mach. Stud. 1976, 8, 249-291.

27. Zimmermann, H.J. Fuzzy Set Theory and Its Applications, 4th ed.; Kluwer Academic Publishers: Boston, MA, USA, 2001.

28. Hwang, C.L.; Yoon, K. Multiple Attribute Decision Making; Springer-Verlag: Berlin, Germany, 1981.

29. Shih, H.S.; Shyur, H.J.; Lee, E.S. An extension of TOPSIS for group decision making. J. Math. Comput. Model. 2007, 45, 801-813.

30. Shen, L.; Olfat, L.; Govindan, K.; Khodaverdi, R.; Diabat, A. A fuzzy multi criteria approach for evaluating green supplier's performance in green supply chain with linguistic preferences. Resour. Conserv. Recycl. 2013, 74, 170-179.

31. Akman, G.; Piskin, H. Evaluating green performance of suppliers via analytic network process and TOPSIS. J. Ind. Eng. 2013, 2013, Article 915241.

32. Wittstruck, D.; Teuteberg, F. Integrating the concept of sustainability into the partner selection process: A fuzzy-AHP-TOPSIS approach. Int. J. Logist. Syst. Manag. 2012, 12, 195-226.

33. Buyukozkan, G.; Cifci, G. A novel hybrid MCDM approach based on fuzzy DEMATEL, fuzzy ANP and fuzzy TOPSIS to evaluate green suppliers. Expert Syst. Appl. 2012, 39, 3000-3011.

34. Kusi-Sarpong, S.; Bai, C.; Sarkis, J.; Wang, X. Green supply chain practices evaluation in the mining industry using a joint rough sets and fuzzy TOPSIS methodology. Resour. Policy 2014, in press.

35. Kannan, D.; de Sousa Jabbour, A.B.L.; Jabbour, C.J.C. Selecting green suppliers based on GSCM practices: Using fuzzy TOPSIS applied to a Brazilian electronics company. Eur. J. Oper. Res. 2014, 233, 432-447.

36. Muralidhar, P.; Ravindranath, K.; Srihari, V. The influence of GRA and TOPSIS for assortment of green supply chain management strategies in cement industry. Int. J. Supply Chain Manag. 2013, 2, 49-55. 
37. Wang, X.; Chan, H.K. A hierarchical fuzzy TOPSIS approach to assess improvement ares when implementing green supply chain initiatives. Int. J. Prod. Res. 2013, 51, 3117-3130.

38. Chen, C.T.; Lin, C.T.; Huang, S.F. A fuzzy approach for supplier evaluation and selection in supply chain management. Int. J. Prod. Econ. 2006, 102, 289-301.

39. Kannan, D.; Khodaverdi, R.; Olfat, L.; Jafarian, A.; Diabat, A. Integrated fuzzy multi criteria decision making method and multi-objective programming approach for supplier selection and order allocation in a green supply chain. J. Clean. Prod. 2013, 47, 355-367.

40. Wang, Y.J.; Lee, H.S. Generalizing TOPSIS for fuzzy multiple-criteria group decision-making. J. Comput. Math. Appl. 2007, 53, 1762-1772.

41. Martinuzzi, A.; Kudlak, R.; Faber, C.; Wiman, A. CSR Activities and Impacts of the Textile Sector. RIMAS Working Papers No. 2, Vienna University of Economics and Business, Vienna, Austria, 2011.

42. Nenni, M.E.; Giustiniano, L.; Pirolo, L. Demand forecasting in the fashion industry: A review. Int. J. Eng. Bus. Manag. 2013, 5, 1-6.

43. D’Amico, S.; Giustiniano, L.; Nenni, M.E.; Pirolo, L. Product lifecycle management and compliance with international standards: A case study analysis in the footwear industry. Int. J. Prod. Lifecycle Manag. 2014, 7, 215-229.

44. Li, W.Y.; Choi, T.M.; Chow, P.S. Risk and benefits brought by formal sustainability programs on fashion enterprises under market disruption. Resour. Conserv. Recycl. 2014, in press.

45. Nenni, M.E.; Giustiniano, L. Increasing integration across the supply chain through an approach to match performance and risk. Am. J. Appl. Sci. 2013, 10, 1009-1017.

46. Govindan, K.; Khodaverdi, R.; Jafarian, A. A fuzzy multi criteria approach for measuring sustainability performance of a supplier based on triple bottom line approach. J. Clean. Prod. 2013, 47, 345-354.

47. Brandenburg, M.; Govindan, K.; Sarkis, J.; Seuring, S. Quantitative models for sustainable supply chain management: Developments and directions. Eur. J. Oper. Res. 2014, 233, 299-312.

48. Govindan, K.; Soleimani, H.; Kannan, D. Reverse logistics and closed-loop supply chain: A comprehensive review to explore the future. Eur. J. Oper. Res. 2015, 240, 603-626.

49. Rostamzadeh, R.; Govindan, K.; Esmaeili, A.; Sabaghi, M. Application of fuzzy VIKOR for evaluation of green supply chain management practices. Ecol. Indicat. 2015, 49, 188-203.

50. Govindan, K.; Devika, K.; Shankar, K.M. Evaluating the drivers of corporate social responsibility in the mining industry with multi-criteria approach: A multi-stakeholder perspective. J. Clean. Prod. 2014, 84, 214-232.

(C) 2015 by the authors; licensee MDPI, Basel, Switzerland. This article is an open access article distributed under the terms and conditions of the Creative Commons Attribution license (http://creativecommons.org/licenses/by/4.0/). 